\title{
O impacto das tecnologias digitais discutido através do filme Ela
}

\section{The impact of digital technologies discussed from the film Her}

\section{Maria Isabel Imbronito}

Doutorado (2008) em Arquitetura e Urbanismo pela Universidade de São Paulo. Docente do curso de Graduação e Mestrado Stricto Sensu em Arquitetura e Urbanismo da Universidade São Judas Tadeu. Docente em Arquitetura e Urbanismo no curso de Graduação em Arquitetura e Urbanismo e no curso de pós-graduação Lato Sensu em Gestão em Projeto de Arquitetura do uniFIAM/FAAM.

<imbronito@gmail.com>

\section{RESUMO}

O presente texto é resultado do primeiro ciclo de debates realizado através do projeto de pesquisa denominado Arquitetura e Cinema, que promoveu um encontro com alunos de graduação e do programa de pós-graduação do curso de Arquitetura e Urbanismo da Universidade São Judas Tadeu. Tendo como tema o homem e a tecnologia contemporânea, o primeiro ciclo consistiu na leitura e discussão de dois filmes: o curta metragem de Miranda July, Somebody (2014) e o longa Her, de Spike Jonze (2013). Através de uma interpretação com base nos filmes e da fundamentação a partir de autores que pesquisam os impactos da tecnologia contemporânea, o texto pretende levantar aspectos para estabelecer uma compreensão acerca da identidade e construção da cultural da era digital, sobretudo a partir do filme de Jonze.

\begin{abstract}
This paper results of the discussions made by the researchers from the group called Architecture and Cinema, conducted inside the Post-Graduation Program in Architecture and Urbanism at São Judas Tadeu University. For the first cycle a theme related to man and contemporary technology was chosen. It consisted of two films: the short film by Miranda July, Somebody (2014) and the long Her, written and directed by Spike Jonze (2013). Through an interpretation based on the narratives presented by the films, the paper brings contributions for the understanding and construction of cultural identity in the digital age.
\end{abstract}

Keywords: Architecture and Films. Communication. Digital culture.

\section{Introdução}

$\mathrm{Na}$ atualidade, a comunicação apresenta um campo de ação expandido pelas novas tecnologias, através das quais transita todo tipo de informação. As implicações das transformações desencadeadas pelos novos meios virtuais e simultâneos relacionados às redes globais são inúmeras, com impacto na linguagem (escrita, visual e audiovisual) e nas percepções humanas. Qualquer recurso de linguagem acionado tem velocidade e pregnância alterados, sem discutir o teor das informações (como a publicação do mundo íntimo e privado), o modo como estas informações se espalham e se multiplicam (postadas e 
compartilhadas pelos próprios usuários), a procedência e originalidade das fontes e a relevância ou superficialidade dos assuntos expostos.

Os novos meios disponíveis e os modos de apropriação e interferência dos usuários são fatores predominantes para a construção e estabelecimento de uma cultura da era digital. Neste sentido, cabe discutir a tecnologia atual e seu impacto em nossas vidas cotidianas, ou seja, de que modo esta tecnologia interfere na cultura material e imaterial, na comunicação em geral e no modo de vida das pessoas.

Ao abordar o impacto dos novos meios provenientes do advento da tecnologia elétrica' nos anos de 1960, McLuhan (1974) adverte que as transformações resultantes do emprego de tais meios repercutem tão profundamente na vida das pessoas que os conteúdos transmitidos perdem importância frente a estas significativas mudanças. Afirma ainda que questionar ou negar o conteúdo transmitido não é o bastante para resistir à penetração dos meios, pois "os efeitos das tecnologias não ocorrem aos níveis das opiniões e dos conceitos: eles se manifestam nas relações entre os sentidos e nas estruturas da percepção, num passo firme e sem qualquer resistência. " Acrescenta que "o artista sério é a única pessoa capaz de enfrentar, impune, a tecnologia, justamente porque é um perito nas mudanças de percepção. " (McLuhan, 1974, p. 34).

Segundo Harvey (2000, p. 293)

as práticas estéticas e culturais tem particular suscetibilidade à experiência cambiante do espaço e do tempo exatamente por envolverem a construção de representações e artefatos espaciais a partir do fluxo da experiência humana.

Considerando o artista especialmente sensível e apto a discutir pontos de vista sobre as transformações da era digital, e os conceitos cambiantes de tempo e espaço relacionados à cultura de cada período, o primeiro ciclo de debates, realizado entre o Grupo de Pesquisa da Pós-Graduação e os alunos de Graduação do Curso de Arquitetura e Urbanismo da Universidade São Judas Tadeu² incluiu um longa metragem ("Her", escrito e dirigido por Spike Jonze,

1 O termo "tecnologia elétrica" é adotado por McLuhan no livro "Os Meios de Comunicação como extensão do homem". Engloba inovações a partir de meados do século XIX: o telégrafo, o rádio, o telefone e a televisão. $O$ computador, existente mas insipiente no momento em que o texto foi escrito, enquadrase para o autor neste mesmo termo. Para as inovações associadas ao computador, hoje utilizaríamos o termo tecnologia digital, era eletrônica ou virtual.

2 O evento realizou-se em 11 e 18 de maio de 2015. 
2013), e um curta metragem ("Somebody", escrito e dirigido por Miranda July, 2014). A partir do filme de Jonze, pretendeu-se constituir uma interpretação no que se refere às questões sobre o homem (humanidade), a máquina, o espaço, o tempo, as relações sociais e os sentidos, tendo em vista as novas tecnologias.

Os filmes exibem a construção de cenários e situações nas quais determinadas características são ressaltadas, conforme o ponto de vista dos escritores-diretores. Através do enfrentamento de questões contemporâneas, que se mostram pertinentes, mas não apresentam vínculo com a verdade, é possível explorar assuntos diversos relacionados à tecnologia da era digital, tanto através dos sentidos (e da linguagem inerente ao próprio cinema), como com base no intelecto. Recorre-se assim a um procedimento segundo o qual o estudo das narrativas é reestruturado através de uma interpretação, que se ampara em referências teóricas, relações lógicas e também sensíveis para a compreensão dos filmes.

\section{Homem-Máquina}

A relação do homem com a máquina é o pretexto do filme "Ela" (HER, Spike Jonze, 2013). Porém, o retrato da máquina no filme de Jonze é exatamente o oposto daquele construído pela mistura de fascínio e terror presentes na era mecânica e difundido em filmes de ficção científica.

Aideia da máquina como mecanismo contempla pressupostos mecânicos, como a divisão e controle de partes, e implica na fragmentação e perda da ideia de totalidade. Conforme Vasconcelos (2009, p. 59), este modelo de máquina é resquício de um modo de conceber o mundo que surge na Era Moderna e perdura fortemente desde o século XVII até o século XIX. A era mecânica tardia, difundida nos processos fabris e, já no século $X X$, também no ambiente doméstico com a adoção de fontes e redes de energia elétrica, contém as crenças constituintes deste campo epistemológico predominante ${ }^{3}$, como a simplicidade, a estabilidade e relação causal dos fenômenos. Seguindo esta estrutura de pensamento, a máquina está associada a uma ação desumanizadora: o conceito de robô está associado a um comportamento não humano, fragmentado, reproduzido em sequências de ações repetitivas e restritas. Ao se estender este modelo ao comportamento social, tem-se o retrato do homem da era mecânica

3 O termo campo epistemológico está aqui associado ao conceito de epistemologia histórica elaborado por M. Foucault, e corresponde ao paradigma geral segundo o qual se estruturam, em uma determinada época, os múltiplos saberes científicos, que por esta razão compartilham determinadas características gerais, apesar de constituírem campos diferentes de conhecimento. (Japiassu, 1997, p. 127). 
como uma espécie de homem-robô vivendo em meio ao ambiente industrial: alheio e limitado, após a aniquilação dos processos que relacionam a psique, a expressão do indivíduo e o corpo social. O tempo e o espaço, tratados de modo homogêneo, são também fragmentados e medidos com instrumentos que regulamentam seu funcionamento, com impacto na organização espacial e na vida das pessoas. Neste mundo regrado, não há possibilidade para as distorções de tempo e espaço, seja através da memória, da percepção e do sensível. 0 cinema retrata o desajuste dos modos tradicionais de existência (ou resistência) frente à era mecânica: Monsier Hulot, o personagem de Tatit, é um clássico exemplar deste desarranjo.

\section{Homem-Robô X Robô-Humano ${ }^{4}$}

A reestruturação da associação e do trabalho humanos foi moldada
pela técnica de fragmentação, que constitui a essência da tecnologia
da máquina. O oposto é o que constitui a essência da tecnologia da
automação. Ela é integral e descentralizadora, em profundidade,
assim como a máquina era fragmentária, centralizadora e superficial
na estruturação das relações humanas. (McLuhan, 1974, p. 21)

No filme de Jonze, a máquina se torna "humana". Em vez do homemrobô, nos deparamos com o robô-humano. A máquina não representa mais uma extensão mecânica (capaz de reproduzir movimentos, forças, trabalhos físicos), mas uma extensão - e expansão - da consciência humana e seu sistema nervoso. Seu funcionamento total e integral está em consonância com os novos paradigmas contemporâneos ${ }^{5}$. Torna-se não apenas capaz de armazenar, mas de produzir memória e formas de expressão e estabelecer relações complexas entre diversos meios, pessoas e com o mundo. Não se trata da humanização da interface - isto é, de como amolecer ou moldar a aparência do sistema operacional - mas de uma transformação profunda nos modos como ele opera,

4 Ver a diferença entre automatização e automação. Conforme Muraco (1969, p. 67), "a automatização é composta por conjuntos abertos de máquinas mecânicas trabalhando a baixas velocidades. A automação compõe-se de sistemas fechados de máquinas eletrônicas operando a velocidades instantâneas".

5 A episteme contemporânea por trás das manifestações das ciências, das artes, da tecnologia e das organizações sociais, remete à velocidade instantânea, a aceitação da existência virtual (quanta), e à concepção do mundo que considera o entrelaçamento dos fenômenos, a imprevisibilidade, a irreversibilidade e a instabilidade. As tecnologias virtuais são o rebatimento deste modo de conceber o mundo, e também fator que acentua e promove o desenvolvimento nesta direção. É possível considerar as tecnologias atuais como "sintomas de determinado estado da cultura, e não sua causa" (Parente, 2001, p.7, ao comentar sobre o texto de LUZ, Novas Imagens: Efeitos e Modelos). 
aproximando-o do comportamento humano, evidentemente destituído da condição física e mortal, mas constituído de iniciativa e consciência de si próprio.

É de se indagar se o homem, ao expandir justamente aquilo que o caracteriza - a consciência, não chegaria a outro ponto que não fosse conceber um espelho de si mesmo. O filme de Jonze aposta na ideia de que tudo o que se projeta ou constrói, como extensão humana aprimorada, torna-se reflexo do próprio homem.

Samantha, o sistema operacional (S.O.) do filme de Jonze, frente ao estranhamento de Theodore (o protagonista) por seu comportamento quase humano, apresenta o impasse resolvido: ambos são o produto de 13 bilhões de anos de evolução e ambos possuem matéria. Fato que coloca Samantha no insólito posto de criação mais recente da natureza.

\title{
Máquina Humana
}

\begin{abstract}
Nesta era da eletricidade, nós mesmos nos vemos traduzidos mais e mais em termos de informação, rumo à extensão tecnológica da consciência. É justamente isto que queremos significar quando dizemos que, a cada dia que passa, sabemos mais e mais sobre o homem. Queremos dizer que podemos traduzir a nós mesmos cada vez mais em outras formas de expressão que nos superam. (McLuhan, 1974, p. 77)
\end{abstract}

No filme de Jonze, o Sistema Operacional (Samantha), como personagem, surge e se constrói sem estabelecer um choque com o espectador. Como os demais aspectos contraditórios e conflituosos presentes no filme, o S.O. é introduzido aos poucos, envolto numa atmosfera amistosa e confortável, enquanto propriamente se inventa, descobre o mundo e se aproxima de Theodore.

Lá pelas tantas, nos deparamos com sua presença no filme, o que nos leva tarde demais a indagar: afinal, o que é Samantha? O que torna sua presença "humana"?

Vários fatores diferentes, a título de especulação, fornecem esta resposta.

\section{A voz de Samantha}

A voz é, quase sempre, tudo o que se tem de Samantha. A voz que se apresenta não é robotizada e contem entonação e dinâmica, que transmitem hesitação, graça, satisfação, tristeza. Apresenta certos "trejeitos" humanos, como cadência e intervalos para respiração, conforme aponta o próprio Theodore. Mas a voz não é, sozinha, responsável pelo efeito humano, pois não está dissociada 
de conteúdo. Neste sentido, os verbos utilizados por Samantha, como to feel ("I feel excited....") não correspondem propriamente à linguagem (e ações) de uma máquina. Estariam estes recursos - semânticos e dinâmicos - dissociados do conteúdo emocional verdadeiro e acionados artificialmente?

\section{O desejo de Samantha}

Relacionada à capacidade de expressar e sentir, está a habilidade de querer. No filme, Jonze nos induz a considerar que a capacidade de decisão de Samantha não obedece apenas a critérios objetivos e racionais, mas está vinculada ao desejo e à preferência, extrapolando para o âmbito do sentimento. (O S.O. se autonomeia "Samantha" porque gosta do som deste nome!).

\section{A presença de Samantha}

A permanência de Samantha é perturbadora. O S.O. tem uma existência autônoma e constante, mesmo quando não é acionado por seu usuário (Theodore). No momento em que a ciência desmonta a ideia da existência de um fenômeno independente do observador ${ }^{6}$, Samanta existe por si só, e não apenas quando se olha para ela. Ela persiste: o tempo todo faz coisas, úteis ou não, de seu interesse ${ }^{7}$. Esta autonomia existencial, para nossa percepção, implica no fato de que Samantha dispõe de um tempo e ocupa um lugar.

\section{O tempo de Samantha}

A relação de Samantha com o mundo cotidiano, através de Theodore, e também com o mundo virtual da informação pura, como sistema operacional, expõe em conflito dois tempos diferentes. O primeiro é o tempo físico, medido pelas palavras, pelos dias, pela espera ao velar o sono humano. $O$ outro é um tempo infinito: devido à velocidade de processamento de Samantha, o tempo da informação é dilatado ao extremo. Em cada fração mínima de tempo cabe uma quantidade infinita de eventos. O tempo de Samantha relaciona-se à velocidade, mas com nova fórmula: velocidade sem distância, revertida em quantidade de informação apreendida no tempo ${ }^{8}$. Além da possibilidade do tempo crescer infinitamente para dentro de si mesmo, estamos diante da imortalidade de Samantha. O tempo dilatado passa a ser medido pelo S.O.

6 Ver os novos paradigmas da ciência (Vasconcellos, 2009, p. 109).

7 "O que você estava fazendo? "É o tipo de pergunta que introduz os diálogos entre Theodore e Samantha.

8 Ver cena em que Samantha lê um livro em fração de segundo - contraposta por cena em que Theodore inicia a leitura de um livro de física e está nas primeiras páginas. 
através das possibilidades e dos espaços infinitos encontrados dentro do tempo cronológico, e passa a ser percebido por Samantha através de sua própria e rápida transformação e evolução.

\title{
O espaço de Samantha
}

Ao ser acionada, tem-se a impressão de que Samantha vem de algum lugar. Mas qual o lugar ocupado por Samantha?

Para falar sobre o impacto da tecnologia elétrica9, McLuhan (1974) constrói a metáfora da implosão. Para o autor, expansão e explosão são características da era mecânica. A ideia de implosão decorre na apreensão, amplificada pelas tecnologias das comunicações, da totalidade da humanidade e do globo. Nos tempos atuais, inclui a totalidade das informações dispostas ao longo dos tempos. O termo implosão repercute para nós, no momento da era da informação e da rede global, na contração total do espaço. Cada usuário aciona a virtude do espaço, ao fazer a informação transitar do espaço virtual à sua própria consciência. No ambiente virtual, o lugar que passa a ter significado é aquele ocupado pela própria consciência, ao acionar informações em disponibilidade permanente. Neste sentido, Samantha ocupa seu próprio lugar.

Se o armazenamento remoto de informações precisa de um dispositivo inato - os sentidos humanos - como meio de contato, prolongado através de equipamentos eletrônicos, Samantha é capaz de transitar absoluta neste ambiente feito para ela, em conexão direta com a informação.

\section{A condição sobre-humana de Samantha}

\begin{abstract}
Poderá o desenraizamento provocado pelas novas tecnologias nos levar a uma emancipação? O que acontecerá com o nosso corpo diante do desaparecimento do espaço e do tempo? (Lyotard citado por Parente, 2001, p.19).
\end{abstract}

A descoberta da condição de Samantha tem uma clara trajetória no filme de Jonze:

- Existe um movimento no qual o S.O. deseja descobrir e experimentar e a condição humana - ou o que seria possuir um corpo. É possível notar uma curiosidade legítima de Samantha pelas coisas mundanas.

- Na experiência do mundo, passa a ocorrer uma interação simbiótica entre Theodore e Samantha. O S.O. pode comportar-se como extensão para

9 Ver nota 3. 
os sentidos humanos (Samantha cumpre o papel de "visão" de Theodore, ao guia-lo de olhos fechados por entre a multidão). Ocorre, simultaneamente, a inversão desta relação: Samantha usa Theodore como "seus" sentidos. Theodore posiciona da câmera do aparelho para que ela perceba o movimento e o som dos trajetos cotidianos e participe da vida. Mais do que isso, vemos no filme a presença única do ator Joaquin Phoenix protagonizando cenas sensórias (barco e vento, neve, refeição ao ar livre), enquanto partilha desta experiência com Samantha.

- A condição conflituosa de Samantha começa a surgir em algumas cenas cuja ação não prescinde do corpo; a praia, o feriado na cabana e a neve enfatizam a distância entre a existência física e a existência virtual.

- Ao adquirir o sentido de permanência e perceber as vantagens de sua condição sobre-humana, o interesse pela matéria se dissipa. O S.O. vai identificar as vantagens de não ter um corpo e a perspectiva limitada do homem sobre a morte. Ela expõe esta nova posição a seus amigos humanos.

É justamente a diferença com relação às habilidades sobre-humanas que afasta Samantha. Ao perceber sua potencialidade pura frente à duplicação dos conceitos de tempo e espaço, opta pelo tempo e espaço de sua natureza virtual. A imagem final construída no filme por Jonze, sobre o tempo dilatado ao infinito, com as palavras representadas pela poeira filmada contra a luz, mostra o grande espaço/tempo vazio que existe entre os fragmentos. O interesse de Samantha irá residir neste tempo expandido a ser preenchido, que se localiza justamente no intervalo dos eventos humanos que a detinham.

Se Samantha vive contida em seu próprio espaço, tendo como ponto de contato a informação, não reproduziria a condição do próprio cérebro humano? Ao expor a máquina humana com sua metáfora digital, Jonze nos faz pensar na própria condição humana. Neste sentido, o filme expõe semelhanças e diferenças entre o homem e a máquina. O que torna Samantha humana são qualidades humanas e, nesse sentido, ela é espelho. Mas ao explorar a potencialidade de Samantha, Jonze traz à tona justamente o limite do homem, no que diz respeito à sua velocidade e finitude.

Recorre-se à citação em Marcondes Filho ao fazer referência a Anders (Marcondes Filho, 1996, p.125), segundo o qual "a máquina angustia porque supera o homem". Diante do homem, a máquina, entre outras coisas, realça nossa própria fragilidade e perecibilidade. 


\section{Consciência e criação artística}

Uma das características de Samantha é sua capacidade de criar. Este atributo é associado ao surgimento do homem como espécie. Desenhos, música, humor, ou editoria de um livro: os exemplos do filme são complexos, não simples associações de fatos.

Além de apontar para uma personagem complexa, a criação artística expõe um traço ambíguo no filme, pois os artifícios que visam ressaltar uma qualidade criativa em Samantha integram-se perfeitamente às cenas, ou seja, viabilizam-se no filme como expressão estética e artística do próprio autor. Está caracterizada uma ilusão na qual uma criação originada de uma personagem é em verdade invenção de Jonze, explorando o cinema como forma de metalinguagem.

\section{Demais elementos para reflexão}

Outros elementos presentes nofilme de Jonze contribuem para enriquecer a discussão sobre a cultura na era digital.

\section{A materialidade e o tempo do filme}

Na sociedade moderna, muitos sentidos distintos de tempo se entrecruzam. Os movimentos cíclicos e repetitivos (...) oferecem uma sensação de segurança num mundo em que o impulso geral do progresso parece ser sempre para a frente e para o alto - na direção do firmamento do desconhecido (Harvey, 2000, p. 187).

Cada vez mais as pessoas vão percebendo que o senso do tato é necessário à existência integral. O ocupante imponderável da cápsula espacial tem que lutar para conservar o senso integrativo do tato. [...] Pode dar-se muito bem que em nossa vida consciente interior, a interação de nossos sentidos constitua o sentido do tato. Ou o tato não seria apenas o contato epidérmico das coisas, mas a própria vida das coisas na mente? (McLuahn, 1974, p. 128).

Aos aspectos inovadores de tempo e espaço problematizados por Jonze a partir das tecnologias atuais se contrapõem à matéria e ao tempo humanos, que dominam o filme e resgatam a esfera física e a existência corpórea. Nesse sentido, o espaço e tempo virtuais não substituem o mundo real, mas surgem como complemento e expansão de possibilidades do mesmo.

Jonze mostra uma cidade que enfatiza o fluxo, tanto humano como de informação, registrado nas pessoas em trânsito conectadas a seus aparelhos 
eletrônicos. Elas locomovem-seno espaço e movem-se na rede simultaneamente, segundo a natureza de cada meio.

$\mathrm{Na}$ escala humana, o espaço real mostra-se materialmente confortável e tátil, característica que permeia o ambiente doméstico, conferindo uma base sólida para o aparato virtual que penetra na vida do homem. Aqui também os ambientes real e virtual coexistem, fortemente ancorados no primeiro.

Já o trabalho de Theodore concentra-se em uma empresa chamada Beautifulhandwrittenletters.com. Em plena era digital e fazendo uso de tecnologia, o ambiente de trabalho remete aos escritórios convencionais, com horários, postos fixos e recepcionista. A estrutura da empresa não se modificou, apesar da tecnologia envolvida: a flexibilidade e liberdade do trabalho a partir das tecnologias dá lugar a uma rotina estabelecida de tempo e espaço.

Esse resgate e sobreposição das referências conhecidas do espaço e do tempo ocorre também nas relações humanas. Ao lado do encontro casual e sexo virtual, está preservado o tempo de aproximação, amadurecimento e afastamento entre as pessoas, o que contrapõe a vertigem ao tempo lento presente no filme, e as relações superficiais às relações profundas.

Efetivamente, Jonze não aborta do mundo pós-moderno o tempo homogêneo, contínuo e linear do calendário e do cronômetro, característico do mundo moderno (Harvey, 2001). O relógio está representado pelo tempo do trabalho e do deslocamento, mas pretende-se fazer que este tempo adquira significado, com o trabalho transformado em expressão, tendo em vista a brevidade da vida humana.

\section{Sentidos e memórias 1 - Sentidos}

Qualquer invenção ou tecnologia é uma extensão ou auto-amputação de nosso corpo, e essa extensão exige novas relações e equilíbrios entre os demais órgãos e extensões do corpo. (McLuhan, 1974, p. 63)

No mundo permeado pela confusão entre os atributos humanos e da máquina, a experiência do mundo fica exaltada pelas novas possibilidades dos sentidos, provenientes das novas extensões tecnológicas do homem. Neste aspecto, a falta de corpo de Samantha é análoga ao nosso próprio embaralhamento dos sentidos na era virtual. Os recursos de imagem, som, memória e informação, expandidos para fora do nosso corpo físico, interferem em nossos aparelhos de percepção.

O sentido tátil, a profundidade e consciência corporal do ambiente tridimensional real é substituído por um sistema de informações que permite 
explorar o espaço virtual como uma estrutura tridimensional complexa. Entretanto, o espaço virtual na tela, apesar de conter todas as informações do espaço, não envolve o observador no sentido de rodeá-lo e contê-lo. No mundo real, pode-se ativar os sentidos para captar o que está atrás ou acima de nós, ou seja, é possível deslocar nossa atenção para fora do ponto focal. Ao proceder deste modo, a atenção volta-se para o fenômeno externo e, simultaneamente, para nosso próprio corpo percebido a si mesmo no espaço. A percepção do espaço-tempo real, como experiência, pressupõe a consciência do corpo. Entrar e mover-se no mundo virtual coloca grande atenção na imagem e inibe os sentidos corporais: a própria percepção do corpo ou a sensação do olho parecem esquecidas. Na tela, o olho surge como um prolongamento periscópico em que a distância do eixo visual afasta a ilusão da unidade e do movimento entre o "sujeito" e o "observador", que se tornam distintos. Alguns meios têm tentado, através de próteses e da interação com o movimento, aproximar o campo visual para ativar nossa visão periférica e ativar conjuntamente os demais sentidos, reequilibrando-os.

No filme, ao lidar com a ausência física de Samantha, Jonze explora o recurso de acionar um sentido no lugar de outro. A música utilizada como foto, ou o sexo sem tato, ou o sexo através do corpo de outra pessoa: embaralhamentos e percepções alteradas para o indivíduo e alteradas socialmente.

O recurso sinestésico é também estendido a outras coisas. Uma informação constante no filme é a presença física da luz do sol, que adquire matéria ao ofuscar a lente, ao ser filmado contra o ar. O registro da luz é mostrado na sua própria trajetória no espaço, ou quando esta impregna uma superfície. Trata-se de algo imaterial a ser percebido no filme como matéria, retratando o invisível e fornecendo uma metáfora para a presença do mundo virtual.

\section{Sentidos e memórias 2 - Memórias}

A memória humana é sobretudo ficção (...) em camadas, cartas, conexões e articulações aleatórias, as lembranças organizam-se em um processo de criação original e veloz, no qual são recobrados pensamentos, sentimentos e ações apreendidas e/ou vivenciadas em diferentes momentos da vida. A imaginação dá curso à sua capacidade criadora e realiza um "todo harmônico", em que o passado é revisitado de acordo com as necessidades do presente e as lembranças ordenadas de forma a garantir uma certa lógica ao discurso, à forma explícita com que a memória se apresenta. (Marcondes Filho, 1996, p. 301-302). 
Samantha não existe a partir de uma identidade com o corpo. Ela existe a partir de sua consciência e memória, e conclui por serem ambas errôneas a cada momento se perde o contato com o que se é, ao se transformar em outra coisa, de modo que permanecer a mesma é impossível e transformar-se é doloroso; e o passado é só uma estória que contamos a nós mesmos. As memórias de Samantha são todas virtuais: não há memórias do corpo em Samantha ou registro da passagem do tempo pelo corpo.

Jonze transforma o registro da presença de Samantha em música composta por ela. É a marca pessoal de sua presença ao compartilhar um momento com Theodore, capaz de acionar a memória daquele instante. A música no lugar da foto nos informa sobre a natureza da foto: não se permitir perder ou confundir a lembrança, congelá-la. A música, entretanto, permite reviver a lembrança, acioná-la. Pode-se recorrer à análise de Giuliano Bruno sobre o filme de Ridley Scott, "Asas do Desejo", segundo a qual "as fotografias são feitas como prova de uma história real, pouco importando qual possa ter sido a verdade dessa história" (Bruno, 1987, citado por Harvey, 2000, p. 280). Significaria, pois, que a prova da lembrança é a base para a construção virtual da memória. Mas a foto é um instante congelado como imagem, enquanto a música (como o cinema) é o momento que transcorre, que se escorre. Podemos recorrer a Harvey, segundo o qual "[...] as fugas de Bach exprimem conceitos de espaço e tempo infinitos". Como uma fuga de Bach, a música de Samantha, transfiguração de foto, apresenta um desenvolvimento constante e cíclico, que representaria o tempo aprisionado na própria estrutura musical, na tentativa de prolongar o momento em transformação repetitiva.

Para Theodore, ao contrário de Samantha, as memórias que retornam e se fundem ao presente são em grande parte físicas. Existe uma alternância de memórias carnais, reais, da antiga relação amorosa de Theodore, se sobrepondo ao tempo com Samantha. Este recurso é um embate à ausência física de Samantha. No tempo presente do filme, o ator Joaquin Phoenix contracena sozinho, rindo ao se comportar como um enamorado, sem ter alguém a seu lado. As cenas parecem constrangedoras. No mundo ancorado no real, a presença ausente de Samantha se torna ilusão ou saudade.

\section{Cartas}

Vivemos hoje numa dessas épocas de crise das antigas ordens de representações e dos saberes, e, mais profundamente, de uma grande complexidade em relação às formas de subjetividade. Nenhuma reflexão séria sobre o devir da cultura contemporânea pode deixar de 


\begin{abstract}
constatar que existe uma enorme multitude de sistemas maquínicos, em particular a mídia eletrônica e a informática, que incidem sobre todas as formas de produção de enunciados, imagens, pensamentos e afetos. É legítima a preocupação de muitos, que se perguntam se o homem e a vida não estariam ameaçados pela crescente ingerência das ciências e da tecnologia sobre a sociedade. (...) Nesse sentido evocamos Guattari, para quem a informática e a tecno-ciência não são nada mais do que formas hiperdesenvolvidas da própria subjetividade. (Parente, 2001, p.14)
\end{abstract}

A atividade desempenhada pelo protagonista Theodore, apesar de apresentar possíveis referências no passado, é colocada no filme como uma profissão. $\mathrm{O}$ personagem escreve cartas de cunho afetivo e pessoal para terceiros.

A emoção é tratada como privilégio humano, uma vez que as cartas não surgem como um tipo de trabalho a ser desempenhado por programas de computador. As cartas simbolizariam um resgate da emoção - no filme, os conteúdos emocionais são tratados com importância e profundidade. $O$ trabalho de Theodore é atribuir ao suposto sentimento alheio uma forma literária - a carta, e o faz ao acionar seu próprio sentimento. Como um intruso nas relações de amor e amizade, e trabalhando continuamente para as mesmas pessoas, acaba por desempenhar um papel ativo nos vínculos destas relações, com poder de transformá-las, influir na memória e no registro das mesmas. Apesar da atividade de Theodore representar algo de difícil assimilação, pois suas implicações são conflituosas, a normalidade com que é retratada no filme anula nossa perplexidade frente ao problema.

De modo análogo à crise de Samantha, quando questiona a veracidade de seus sentimentos ou a possibilidade de serem resultado de simples programação, seriam verdadeiros os sentimentos presentes nas cartas escritas por Theodore? Corresponderão àqueles do próprio sujeito original? É possível que aquele sentimento inscrito na carta não exista em sujeito algum? Cumpririam as cartas papel semelhante às fotos, de evidência da estória vivida, tendo sido ou não verdade?

Por outro viés, a atitude de terceirizar cartas de teor emocional relacionase com a atitude de Samantha ao acionar uma mulher, como corpo físico, para representá-la durante o sexo. Para Jonze, a terceirização do corpo causa conflito e estranheza em Theodore, enquanto as cartas, que representam a terceirização da emoção, são elogiadas.

O trabalho deTheodore utiliza tecnologia. Ele dita as cartas ao computador, que as transcreve combinando a caligrafia do sujeito original em papeis de 
carta que conferem, ao final, uma presença física à carta: ela é envelopada e postada. Mensagens "prontas" poderiam ser entregues virtualmente ou mesmo impressas pela pessoa que as recebe. Jonze aposta na valorização da matéria em contraponto ao mundo virtual conferindo maior importância ao registro físico de um processo absolutamente desvirtuado.

Ao final, quando Theodore publica um livro com suas melhores cartas, Jonze faz as cartas retornarem à forma física e recoloca o impasse entre o público e o privado. Cartas sob medida para relações específicas acabam publicamente divulgadas, e espelham o universo emocional de todos, escancarando a condição privada das relações humanas e abrangendo padrões de comportamento que são coletivos. A leitura e interpretação das cartas acionará, no momento certo, o vínculo subjetivo e interno em cada leitor, retornando o conteúdo à esfera individual, mas servindo a outro sujeito.

Samantha, por sua vez, estende seu padrão emocional de relação com Theodore a um grande número de usuários, sem perder a individualidade de cada um destes vínculos. A rigor, a imagem que se segue à revelação da "traição" de Samantha, que mostra o trânsito de humanos conectados cada qual a seu sistema operacional, nos leva a indagar se estariam todos conectados a um único sistema onipresente e se, de fato, a individualidade, respeitada e valorizada no filme de Jonze, não se torna ilusória nos tempos de expansão da consciência em forma coletiva e nebulosa.

\section{Conclusão}

...é um erro pensar que o virtual substitui o real, ou que as telecomunicações e a telepresença vão pura e simplesmente substituir os deslocamentos físicos e os contatos diretos. A perspectiva da substituição negligencia a análise das práticas sociais efetivas e parece cega à abertura de novos planos de existência, que são acrescentados aos dispositivos anteriores ou os complexificam em vez de substituí-los. (Lévy, 2010, p. 217).

... as grandes invenções técnicas não permitem apenas fazer"a mesma coisa" mais rápido, com mais força ou em maior escala. Permite, sobretudo, que se faça, sinta ou organize de outra forma. Levam ao desenvolvimento de novas funções ao mesmo tempo em que nos obrigam a reorganizar o sistema global das funções anteriores. A problemática da substituição nos impede de pensar, receber ou fazer acontecer o qualitativamente novo, quer dizer, os novos planos de existência virtualmente trazidos pela inovação técnica. (Lévy, 2010, p. 223). 
A partir da análise do filme de Jonze, é possível aventar algumas implicações das novas tecnologias virtuais na formação da cultura da era digital e relacionar os eventos narrados a diversos autores, entre filósofos e estudiosos da produção do espaço e da cultura, das tecnologias e das comunicações, que apontam para uma convergência destes fenômenos.

Os principais aspectos a serem ressaltados, presentes na narrativa, relacionam-se às categorias de tempo, espaço e memória, que são fundamentais para a existência humana. Estes três conceitos, culturalmente constituídos, recentemente tem passado por transformações abruptas e perceptíveis no prazo de existência de um indivíduo.

Mais do que apresentar uma versão definitiva de como a cultura digital se conforma, os apontamentos levantados indicam novos modelos de relações humanas, relação com a informação, com as artes e com o conhecimento. As possibilidades de expansão, colaboração e sincronia entre pessoas, máquinas e informações demonstram a potencialidade para enfrentamento dos problemas que a humanidade possa se deparar no futuro. Este é o lado promissor da tecnologia.

Entretanto, não há um único conflito retratado nos filmes que aborde a esfera de ação coletiva de modo abrangente. As tecnologias, tratadas como prolongamento do universo individual, partem desta condição de expressão polifônica inserida dentro de um sistema neutro de existência coletiva. A análise de um fenômeno parecido é feita por Harvey (2001, p. 283), sobre o filme "Asas do Desejo". Os anjos, que tem acesso aos pensamentos dos homens, estão diante de um mosaico polifônico de perturbações internas sem sentido aparente. $O$ filme de Jonze também transfere para o mundo interno e individual o foco dos conflitos denunciando um deslocamento do homem contemporâneo frente aos comportamentos e dinâmicas da atualidade.

Se alguns autores consideram que as novas tecnologias possibilitam o afloramento da individualidade, outros aliariam a este fenômeno o surgimento de uma consciência global na qual as ações humanas interligadas se percebem como atuantes e influentes. Ampliar a consequência dos movimentos coletivos com base na iniciativa do sujeito consciente é, sem dúvida, um desafio que contém grande potencialidade de ação e o poder de transformar o futuro.

Referências

CYRILLO, Mars. O Filme "Ela" e o estado atual da inteligência artificial. Imasters tecnologia. Postado em 18/02/2014. Disponível em: <http://imasters.com.br/ gerencia-de-ti/tendencias/0-filme-ela-e-o-estado-da-inteligencia-artifical/>. Acesso em: 22/05/2015. 
GIANNETTI, José. A ilusão da alma. Biografia de uma ideia fixa. São Paulo: Companhia das Letras, 2010.

HARVEY, David. Condição pós-moderna. São Paulo: Edições Loyola, 2000.

JAPIASSU, Hilton. Introdução ao pensamento epistemológico. Rio de Janeiro: Livraria Francisco Alves Editora, 1997.

LÉVY, Pierre. Cibercultura. São Paulo: Editora 34, 3. ed., 2010.

MARCONDES FILHO, Ciro (org.), COLETIVO NTC. Pensar pulsar. Cultura comunicacional, tecnologias, velocidade. São Paulo: Edições NTC, 1996.

MCLUHAN, Marshall. Os meios de comunicação como extensões do homem. São Paulo: Cultrix, 1974.

PARENTE, André (org.) Imagem Máquina. A era das tecnologias do virtual. São Paulo: Editora 34, 2001 (1ª reimpressão, $3^{a}$ edição).

VASCONCELLOS, Maria José Esteves de. 0 pensamento sistêmico: o novo paradigma da ciência. Campinas: Papirus, 2002, 8 ed., 2009)

VIRILIO, Paul. O espaço crítico. São Paulo, Editora 34, 1995.

\section{Filmes}

HER. Texto, Direção e Produção: Spike Jonze. Los Angeles, Warner Bross, 2013.

SOMEBODY.Texto e Direção:Miranda July.MiuMiu, Hi!Productions, 2014. Disponível em: <http://www.miumiu.com/en/women tales/8/film>. Acesso em: 22/05/2015.

Recebido em: 15/10/2015

Aceito em: 23/11/2015

Endereço do Autor:

Maria Isabel Imbronito <imbronito@gmail.com>

Universidade São Judas Tadeu

Av. Vital Brasil, 1000 - Butantã

CEP05503-001

São Paulo, SP - Brasil 